\title{
Stable coexistence of two Caldicellulosiruptor species in a de novo constructed hydrogen- producing co-culture
}

\author{
Ahmad A Zeidan*, Peter Rådström, Ed WJ van Niel
}

\begin{abstract}
Background: Mixed culture enrichments have been used frequently for biohydrogen production from different feedstock. In spite of the several advantages offered by those cultures, they suffer poor $\mathrm{H}_{2}$ yield. Constructing defined co-cultures of known $\mathrm{H}_{2}$ producers may offer a better performance than mixed-population enrichments, while overcoming some of the limitations of pure cultures based on synergies among the microorganisms involved.

Results: The extreme thermophiles Caldicellulosiruptor saccharolyticus DSM 8903 and C. kristjanssonii DSM 12137 were combined in a co-culture for $\mathrm{H}_{2}$ production from glucose and xylose in a continuous-flow stirred tank reactor. The co-culture exhibited a remarkable stability over a period of 70 days under carbon-sufficient conditions, with both strains coexisting in the system at steady states of different dilution rates, as revealed by species-specific quantitative PCR assays. The two strains retained their ability to stably coexist in the reactor even when glucose was used as the sole growth-limiting substrate. Furthermore, $\mathrm{H}_{2}$ yields on glucose exceeded those of either organism alone under the same conditions, alluding to a synergistic effect of the two strains on $\mathrm{H}_{2}$ production. A maximum $\mathrm{H}_{2}$ yield of $3.7 \mathrm{~mol}$ (mol glucose) ${ }^{-1}$ was obtained by the co-culture at a dilution rate of $0.06 \mathrm{~h}^{-1}$; a higher yield than that reported for any mixed culture to date. A reproducible pattern of population dynamics was observed in the co-culture under both carbon and non-carbon limited conditions, with C. kristjanssonii outgrowing C. saccharolyticus during the batch start-up phase and prevailing at higher dilution rates. A basic continuous culture model assuming the ability of $C$. saccharolyticus to enhance the growth of $C$. kristjanssonii could mimic the pattern of population dynamics observed experimentally and provide clues to the nature of interaction between the two strains. As a proof, the cell-free growth supernatant of C. saccharolyticus was found able to enhance the growth of C. kristjanssonii in batch culture through shortening its lag phase and increasing its maximum biomass concentration by ca. $18 \%$.

Conclusions: This study provides experimental evidence on the stable coexistence of two closely related organisms isolated from geographically-distant habitats under continuous operation conditions, with the production of $\mathrm{H}_{2}$ at high yields. An interspecies interaction is proposed as the reason behind the remarkable ability of the two Caldicellulosiruptor strains to coexist in the system rather than only competing for the growth-limiting substrate.
\end{abstract}

\section{Background}

In natural ecosystems, mixed microbial populations are the rule rather than the exception. Distinct microbial populations frequently interact with each other in a variety of ways giving rise to many beneficial effects and,

\footnotetext{
* Correspondence: ahmad.zeidan@tmb.lth.se
Applied Microbiology, Lund University, Getingevägen 60, SE-222 41 Lund,

* Correspondence: ahmad.zeidan@tmb.lth.se
Applied Microbiology, Lund University, Getingevägen 60, SE-222 41 Lund, Sweden
}

(c) 2010 Zeidan et al; licensee BioMed Central Ltd. This is an Open Access article distributed under the terms of the Creative Commons Attribution License (http://creativecommons.org/licenses/by/2.0), which permits unrestricted use, distribution, and reproduction in any medium, provided the original work is properly cited.

therefore, it is not surprising that mixed cultures possess broader metabolic capabilities and show more robustness to environmental fluctuations than individual populations [1]. In biotechnology, continuous enrichment techniques have been used for obtaining stable microbial consortia adapted to continuous culture conditions, which is especially valuable in a continuous-flow commercial process [2]. The use of such enrichments has 
indeed been proven useful in several applications, such as anaerobic digestion and biopolymer and solvent production [3].

Alternatively, microbial communities can be built, where the diversity and metabolic capabilities of the community can be tuned by careful selection of the individual members for achieving improved or new structures and functions [4]. This approach has been widely adapted in food fermentations [5,6] and successfully employed for lab-scale bioethanol [7-9], acetic acid [10] and lactic acid [11] production. It also provides an essential tool for fundamental studies on the different mechanisms of microbial interactions [12-16]. Although the approach appears interesting, the stability of these artificial communities is remarkably difficult to achieve for various reasons, as discussed by Weibel [4]. To date, there appears to be only few studies that report on the construction of co-cultures consisting of two or more bacterial species that can stably coexist over a long period of time [17-21].

Owing to its high economic value and wide range of applications in the chemical industry, $\mathrm{H}_{2}$ has been a subject of increasing interest in recent years. Considerable research efforts have been dedicated to producing $\mathrm{H}_{2}$ by biological conversion of biomass via dark fermentation, with a notable emphasis on the use of mixedculture enrichments [22-25]. The starting culture is usually derived from samples of compost or anaerobic treatment sludge [26] and in spite of the high volumetric $\mathrm{H}_{2}$ production rates achieved by these cultures, $\mathrm{H}_{2}$ yields usually do not exceed two moles per mole of hexose sugar converted [3]. Since the process is always coupled to biowaste treatment, high yields may not be viewed as essential. However, dark fermentation allows the release of up to 4 moles of $\mathrm{H}_{2}$ per mole of hexose sugar [27], and therefore, if $\mathrm{H}_{2}$ is to be produced from energy crops, this maximum yield should be aimed for.

Construction of 'designer' $\mathrm{H}_{2}$-producing communities can be foreseen as a possible way to overcome some of the issues inherent to the use of undefined consortia, most notably the low $\mathrm{H}_{2}$ yields [22,28]. In a previous study, the extreme thermophiles Caldicellulosiruptor saccharolyticus and C. kristjanssonii have been combined in a $\mathrm{H}_{2}$-producing co-culture with the primary aim of improving the rate of glucose consumption during co-fermentation with xylose [28]. A more interesting outcome of this co-culture was its ability to produce $\mathrm{H}_{2}$ at a higher yield than that of either organism alone. However, the fermentations were carried out in batch mode and the stability of the co-culture in a continuous system remained questionable. This is particularly important since in practical application chemostat conditions are more likely to be used. In the present work, we demonstrate $\mathrm{H}_{2}$ production at high yields in a continuously-stirred tank reactor (CSTR) by a stable coculture of C. saccharolyticus and C. kristjanssonii under chemostat conditions. Due to the lack of morphological differences between the two species, a quantitative PCR (qPCR) assay for monitoring the growth of each organism in the co-culture was developed. In addition, a proof of the ability of one or more products of $C$. saccharolyticus cells to enhance the growth of C. kristjanssonii could be obtained. The remarkable potential of the two, closely related, strains to stably coexist under nutrient-limited conditions, as could be captured in a simple mathematical model describing the system, is discussed.

\section{Materials and methods \\ Microorganisms}

C. saccharolyticus DSM 8903 (also, ATCC 43494) and C. kristjanssonii strain I77R1B (DSM 12137; ATCC 700853) were purchased from the Deutsche Sammlung von Mikroorganismen und Zellkulturen (DSMZ; Braunschweig, Germany).

\section{Inoculum development}

C. saccharolyticus and C. kristjanssonii were individually subcultured twice at $70^{\circ} \mathrm{C}$ in $50 \mathrm{~mL}$ modified DSM medium 640 [28] containing the same sugar(s) used in the subsequent fermentation $\left(10 \mathrm{~g} \mathrm{~L}^{-1}\right)$ under $\mathrm{N}_{2}$ atmosphere in $250-\mathrm{mL}$ crimped-seal bottles. After the optical density at $620 \mathrm{~nm}\left(O D_{620}\right)$ of the second subculture has reached 0.3 - 0.4, it was used to inoculate the bioreactor at a level of $15 \%\left(\mathrm{v} \mathrm{v}^{-1}\right)$. For initiating the co-culture, an equal volume of each organism was used.

\section{Bioreactor setup}

The organisms were grown in a jacketed, 3-L stirredtank bioreactor (Applikon, Schiedam, The Netherlands) at $70 \pm 1^{\circ} \mathrm{C}$. The bioreactor was equipped with an ADI 1025 Bio-Console and an ADI 1010 Bio-Controller (Applikon, Schiedam, The Netherlands). A modified DSM medium 640 was used for all cultivations at a working volume of $1 \mathrm{~L}$. A sterile solution of glucose and/or xylose was added to the medium after sterilization to the required concentration. The medium was continuously sparged with $\mathrm{N}_{2}$ gas containing less than 5 ppm $\mathrm{O}_{2}$ (AGA Gas AB, Sundbyberg, Sweden) at $100 \mathrm{~mL}$ $\mathrm{min}^{-1}$ and stirred at $300 \mathrm{rpm}$. The $\mathrm{pH}$ was maintained automatically at $6.7 \pm 0.1$ at the operating temperature, using $3 \mathrm{M} \mathrm{NaOH}$ as a titrant. The medium was rendered completely anaerobic by the addition of cysteine- $\mathrm{HCl}$ at a final concentration of $1 \mathrm{~g} \mathrm{~L}^{-1}$ prior to inoculation. After an initial growth in batch mode, the bioreactor was fed at the end of the exponential growth phase with a fresh medium, having a similar composition to the start-up medium except for the omission of 
cysteine-HCL, at $0.04 \mathrm{~h}^{-1}$. The feed bottle was continuously sparged with $\mathrm{N}_{2}$ to avoid medium displacement by air. After a steady state has been attained, a stepwise increase in the dilution rate $(D)$ was carried out. Steady states were assessed after at least 5 volume changes through constant $\mathrm{H}_{2}$ and $\mathrm{CO}_{2}$ production rates and constant biomass concentration.

\section{Sampling}

Gas samples from the bioreactor's headspace were regularly analyzed for $\mathrm{H}_{2}$ and $\mathrm{CO}_{2}$ composition. Culture samples were regularly withdrawn for monitoring the biomass concentration. In addition, $10 \mathrm{~mL}$ culture samples were aseptically withdrawn and cells were harvested by centrifugation at $5,000 \times g$ and $4^{\circ} \mathrm{C}$ for $12 \mathrm{~min}$, washed twice with $1 \times$ phosphate-buffered saline (PBS) by centrifugation and stored at $-20^{\circ} \mathrm{C}$ for genomic DNA extraction. The supernatant was further clarified by passing through a $0.2-\mu \mathrm{m}$ cellulose acetate filter (Advantec, Tokyo, Japan) and analyzed for sugar consumption and metabolite formation.

\section{Effect of C. saccharolyticus cell-free growth supernatant on C. kristjanssonii}

The growth supernatant of C. saccharolyticus was evaluated for its ability to enhance the growth of C. kristjanssonii in batch cultures. Growth supernatants from 50 -mL cultures of each organism were collected by centrifugation at $12,000 \times g$ and $4^{\circ} \mathrm{C}$ for $6 \mathrm{~min}$. The supernatant of $C$. kristjanssonii culture was discarded and the cell pellet was retained. The supernatant of C. saccharolyticus culture was filtered through a sterile, 0.2- $\mu \mathrm{m}$ pore-size filter (Sarstedt, Nümbrecht, Germany) to obtain a cell-free spent culture broth in which C. kristjanssonii cells were resuspended. All manipulations were carried out inside an anaerobic glove box (Plas Labs Inc., MI, USA) under an atmosphere of $\mathrm{N}_{2}$ $\mathrm{H}_{2}-\mathrm{CO}_{2}$ (0.85:0.10:0.05). The 50-mL resuspended culture of C. kristjanssonii was combined with either 50 or 100 $\mathrm{mL}$ of untreated C. kristjanssonii inoculum to inoculate $1 \mathrm{~L}$ modified DSM 640 medium, containing $10 \mathrm{~g} \mathrm{~L}^{-1}$ glucose as a substrate, in the bioreactor. The fermentations were conducted in batch mode under the same conditions described above and biomass concentration was monitored at regular intervals.

\section{Analytical methods}

The concentrations of $\mathrm{H}_{2}$ and $\mathrm{CO}_{2}$ were determined by gas chromatography, using a dual-channel CP 4900 Micro-GC (Varian, Middelburg, The Netherlands). $\mathrm{H}_{2}$ was analyzed on a molecular sieve column (CP-MolSieve $5 \AA$ PLOT) with the injector and column temperatures at 80 and $100^{\circ} \mathrm{C}$, respectively, whereas $\mathrm{CO}_{2}$ was analyzed on a CP-PoraPLOT Q column with the temperature of both the injector and the column at $80^{\circ} \mathrm{C}$. The carrier gases for the MolSieve and the PoraPLOT Q columns were $\mathrm{N}_{2}$ and $\mathrm{He}$, respectively, at $150 \mathrm{kPa}$. Each channel was equipped with a micro-machined thermal conductivity detector. Sugars, organic acids and ethanol were separated by high-performance liquid chromatography (HPLC; Waters Corporation, Milford, MA) on an Aminex HPX-87H column (Bio-Rad, Hercules, CA) at $45^{\circ} \mathrm{C}$. Sulfuric acid $(5 \mathrm{mM})$ was used as the mobile phase at a flow rate of $0.6 \mathrm{~mL} \mathrm{~min}{ }^{-1}$. The analytes were detected on a refractive index detector (RID-6A; Shimadzu, Tokyo, Japan).

\section{Biomass determination}

A U-1800 spectrophotometer (Hitachi, Tokyo, Japan) was used for regular monitoring of the $O D_{620}$. For cell dry weight (CDW) determination, $10 \mathrm{ml}$ of culture were transferred to $15-\mathrm{mL}$ dried, pre-weighed Falcon tubes and centrifuged at 5,000 $\times g$ for $15 \mathrm{~min}$, washed with deionized $\mathrm{H}_{2} \mathrm{O}$ and dried at $70^{\circ} \mathrm{C}$ to a constant weight. Enumeration of C. saccharolyticus and C. kristjanssonii in their pure cultures was performed by direct microscopic count, using a Bürker-pattern counting chamber (Marienfeld, Lauda-Königshofen, Germany).

\section{DNA extraction}

Genomic DNA was extracted from washed, frozen cell pellets using the Easy-DNA Kit (Invitrogen, San Diego, $\mathrm{CA})$, according to the manufacturer's protocol. For complete RNA degradation, DNA preparations in TrisEDTA buffer (TE buffer; pH 8) were incubated with RNase A $\left(40 \mu \mathrm{g} \mathrm{mL}^{-1}\right)$ for $30 \mathrm{~min}$ at $37^{\circ} \mathrm{C}$. The concentration and purity of DNA were analyzed spectrophotometrically in an Eppendorf Biophotometer (Hamburg, Germany). Aliquots of DNA in TE buffer were stored at $-20^{\circ} \mathrm{C}$ until use.

\section{Real-time PCR assays}

qPCR assays were developed for quantifying C. saccharolyticus and C. kristjanssonii in their co-culture. For this, specific oligonucleotide primer pairs based on differences in the 16S rRNA gene sequence of the two species, as retrieved from the GenBank Sequence Database http://www.ncbi.nih.gov/Genbank/, were designed

Table 1 Real-time PCR primers for quantification of C. saccharolyticus and C. kristjanssonii in their co-culture

\begin{tabular}{lllc}
\hline Target & Primer & Sequence & $\begin{array}{c}\text { Product size } \\
\text { (bp) }\end{array}$ \\
\hline C. saccharolyticus & S_572F & GGTGCGTAGGCGGCTATGCG & 448 \\
& S_1019R & CCCACCCTTCGGGCAGGTC & \\
C. kristjanssonii & K_612F & GGAGCGCTCAAGACTGCCGG & 317 \\
& Ks_928R & TCCACCGCTTGTGGGGCC & \\
\hline
\end{tabular}


(Table 1). The gene sequences were compared for differences using the ClustalW2 multiple sequence alignment program http://www.ebi.ac.uk/Tools/clustalw2/. Realtime PCR amplification and detection were performed in the LightCycler 2.0 Instrument (Roche Diagnostics, Mannheim, Germany). The PCR mixture $(20 \mu \mathrm{l})$ contained $1 \times$ Tth PCR buffer, $1 \mathrm{U}$ Tth DNA polymerase (both, Roche Diagnostics), $1.5 \mathrm{mM} \mathrm{MgCl} 2,0.2 \mathrm{mM}$ dNTPs (both, Fermentas, St. Leon-Rot, Germany), 1× SYBR Green I solution (Roche Diagnostics) and $4 \mu \mathrm{l}$ DNA template solution, in addition to the forward and reverse primers. The primer concentration in the PCR mixture was $0.125 \mu \mathrm{M}$ (each) for $C$. saccharolyticusspecific assay and $0.5 \mu \mathrm{M}$ (each) for C. kristjanssoniispecific assay. Blanks containing sterile MilliQ water (Millipore; Billerica, MA, USA) instead of the DNA templates and negative controls containing DNA template of the non-targeted species were included in each run. The LightCycler amplification protocol started with an initial denaturation at $95^{\circ} \mathrm{C}$ for $60 \mathrm{~s}$, followed by 45 cycles of denaturation at $95^{\circ} \mathrm{C}$ for $0 \mathrm{~s}$, annealing and fluorescence acquisition at $63^{\circ} \mathrm{C}$ for $5 \mathrm{~s}$, and elongation at $72^{\circ} \mathrm{C}$ for $25 \mathrm{~s}$. The specificity of the primers was validated so that the quantitative signals detected for the target strain were not affected by the presence of genomic DNA of the other strain. For that, a melting-curve analysis, consisting of heating at $95^{\circ} \mathrm{C}$ for $0 \mathrm{~s}$ and $50^{\circ} \mathrm{C}$ for $15 \mathrm{~s}$ followed by an increase in temperature by $0.2^{\circ}$ $\mathrm{C} / \mathrm{s}$ up to $90^{\circ} \mathrm{C}$, was performed. In addition, the PCR products were further confirmed by agarose-gel electrophoresis.

Quantification was achieved by determining the crossing point $(\mathrm{Cp})$ of the sample - that is, the fractional cycle number that corresponds to the maximum of the second derivative of the amplification curve - and comparing to standards. For preparing the standards, pure cultures of C. saccharolyticus and C. kristjanssonii were individually grown on glucose in 3-L bioreactors under the same conditions described above, albeit in batch mode. Culture samples of each organism were collected at different time intervals for cell count and genomic DNA extraction. A first standard curve between DNA concentration and cell number was plotted to validate the DNA extraction protocol and the capacity of the extraction kit. DNA preparations from samples of varying cell numbers were then used, after appropriate dilution, as templates for $\mathrm{qPCR}$. The mean $\mathrm{Cp}$ of two independent real-time PCR replicates was plotted against the logarithm of the corresponding cell count to obtain a second standard curve. For quantitative determination C. saccharolyticus and C. kristjanssonii in different samples of their co-culture, the second standard was regenerated for each species with every run in the
LightCycler to overcome any variability in the amplification efficiency.

\section{Co-culture model}

A mathematical model was built to simulate the stable co-existence of C. saccharolyticus (organism 1) and C. kristjanssonii (organism 2) in the co-culture, with glucose as the main carbon and energy source. The model is based on the general mass balance equations and the proposed release of a compound $(E)$ by $C$. saccharolyticus with the ability to enhance biomass yield and the maximum specific growth rate of C. kristjanssonii. The continuous co-culture system can be described by three relevant differential equations (growth of $C$. saccharolyticus, growth of C. kristjanssonii and glucose consumption, respectively):

$$
\begin{aligned}
& \frac{d x_{1}}{d t}=\left(\mu_{1}-D\right) x_{1} \\
& \frac{d x_{2}}{d t}=\left(\mu_{2}-D\right) x_{2} \\
& \frac{d s}{d t}=D\left(s_{0}-s\right)-\frac{1}{Y_{s x_{1}}} \mu_{1} x_{1}-\frac{1}{Y_{s x_{2}}} \mu_{2} x_{2}
\end{aligned}
$$

where $x_{1}$ is the biomass concentration of C. saccharolyticus ( $\left(\mathrm{CDWW} \mathrm{L} \mathrm{L}^{-1}\right), x_{2}$ is the biomass concentration of C. kristjanssonii (gCDW L $\left.\mathrm{L}^{-1}\right), s_{0}$ is the glucose concentration in the feed $\left(\mathrm{mmol} \mathrm{L}^{-1}\right), s$ is the residual glucose concentration $\left(\mathrm{mmol} \mathrm{L}^{-1}\right)$, and $t$ is the fermentation time (h). The biomass yield coefficient $Y_{s x_{1}}$ [gCDW $\left(m m o l\right.$ glucose $\left.\mathrm{e}^{-1}\right)$ ], is considered to be constant, whereas $Y_{s x_{2}}$ and the growth rates $\left(\mu_{1}\right.$ and $\left.\mu_{2}\right)$ are each a function of several variables as explained below.

The growth rate of C. saccharolyticus and C. kristjanssonii can be described by Monod equations:

$$
\begin{aligned}
& \mu_{1}=\mu_{\max 1} \frac{s}{K_{s_{1}}+s} \\
& \mu_{2}=\mu_{\max 2} \frac{s}{K_{s_{2}}+s}
\end{aligned}
$$

in which $\mu_{\max 1}$ and $\mu_{\max 2}$ are the maximum specific growth rates $\left(\mathrm{h}^{-1}\right)$ of $C$. saccharolyticus and C. kristjanssonii, respectively, and $K_{s_{1}}$ and $K_{s_{2}}$ are the Monod constants for glucose $\left(\mathrm{mmol} \mathrm{L}^{-1}\right)$ for $C$. saccharolyticus and C. kristjanssonii, respectively. 
The relationship between the concentration of the proposed excreted product $(E)$ and $C$. saccharolyticus biomass concentration is as follows:

$$
E=\kappa x_{1}
$$

with $\kappa$ as the specific yield factor $\left(\mathrm{mmol} \mathrm{gCDW}^{-1}\right)$. The increase in the maximum specific growth rate and biomass yield of $C$. kristjanssonii by the effect of compound $E$ can be described as:

$$
\begin{aligned}
& \mu_{\max 2}=\mu_{\max 2}^{0}-\left(\mu_{\max 2}^{\prime}-\mu_{\max 2}^{0}\right) \frac{E}{E_{C}} \\
& Y_{s x_{2}}=Y_{s x_{2}}^{0}-\left(Y_{s x_{2}}^{\prime}-Y_{s x_{2}}^{0}\right) \frac{E}{E_{C}}
\end{aligned}
$$

with $\mu_{\max 2}^{0}$ and $\mu_{\max 2}^{\prime}$ as the maximum specific growth rates in the absence of compound $E$ and in its presence at the critical concentration $\left(E_{\mathrm{C}}\right)$, respectively. Likewise, $Y_{s x_{2}}^{0}$ and $Y_{s x_{2}}^{\prime}$ are the biomass yield factors in the absence of compound $E$ and in its presence at the critical concentration, respectively.

Values of the different parameters included in the model are listed in Additional file 1 (Table S1). The set of differential equations was solved using Matlab (R2009a; The MathWorks, Inc.).

\section{Results}

\section{Hydrogen production and stability of the co-culture under non-carbon limitation}

C. saccharolyticus and C. kristjanssonii were grown together in a CSTR at various dilution rates, ranging from 0.04 to $0.3 \mathrm{~h}^{-1}$, over a period of 70 days. The total sugar concentration in the feed was $10 \mathrm{~g} \mathrm{~L}^{-1}$ (glucose and xylose; $1: 1)$. At least 8 volume changes were required to attain a steady state at lower dilution rates, while up to 20 volume changes were required at the higher ones. Neither glucose nor xylose in the feed was completely consumed at any of the dilution rates tested, suggesting that the co-culture was not carbon limited (Table 2). The residual sugar concentration increased with the dilution rate, and a similar trend was observed for biomass concentration. The specific xylose consumption rate was considerably higher than that of glucose at all dilution rates (see Table S2.1 in Additional file 2). The main metabolic end products of glucose and xylose fermentation were $\mathrm{H}_{2}, \mathrm{CO}_{2}$ and acetate, whereas lactate was formed in minor quantities. Complete carbon and electron recoveries could be obtained (see Table S2.2 in Additional file 2).
Both the volumetric and specific $\mathrm{H}_{2}$ production rates ( $Q_{\mathrm{H}_{2}}$ and $q_{\mathrm{H}_{2}}$, respectively) markedly increased with the dilution rate (Table 2). The maximum volumetric hydrogen production rate obtained was $11.6 \mathrm{mmol} \mathrm{L}^{-1}$ $\mathrm{h}^{-1}$ at 0.25 and $0.3 \mathrm{~h}^{-1}$. On the other hand, $\mathrm{H}_{2}$ yield $\left(Y_{\mathrm{H}_{2}}\right)$ was inversely proportional to the dilution rate, with the maximum of $3.6 \mathrm{~mol} \mathrm{H}_{2}$ per mol of hexose equivalent obtained at $0.06 \mathrm{~h}^{-1}$ (Table 2). This yield represents $90 \%$ of the maximum theoretical yield that can be obtained from glucose during dark fermentative hydrogen production. The biomass yield $\left(Y_{\mathrm{sx}}\right)$ increased sharply at $D>0.15 \mathrm{~h}^{-1}$ (Table 2), which could be due to the accumulation of a storage material, e.g., glycogen.

qPCR assays were used to assess the ability of $C$. saccharolyticus and C. kristjanssonii to coexist under steady-state conditions and to monitor the population dynamics during the continuous operation of the reactor. The results showed that, in spite of the variation in population dynamics at different steady states, the two organisms could stably coexist over the whole range of dilution rates tested (Figure 1). C. kristjanssonii outgrew C. saccharolyticus by the end of the batch start-up phase, and at steady states of $D>0.06 \mathrm{~h}^{-1}$. On the other hand, $C$. saccharolyticus prevailed at the lowest $D$, i.e., $0.04 \mathrm{~h}^{-1}$. The specificity of the designed primers was confirmed throughout the assays by melting-curve analysis, where only one amplicon with the expected melting temperature was detected. Additionally, the PCR products were analyzed by agarose-gel electrophoresis, where only one band of the expected size could be detected (data not shown).

\section{Carbon limitation with two sugars}

In order to study the effect of carbon limitation on $\mathrm{H}_{2}$ production and the possibility of coexistence of the two species, the total sugar concentration in the feed was reduced to $4 \mathrm{~g} \mathrm{~L}^{-1}$ (glucose and xylose; 1:1). Based on the co-culture performance under non-carbon limitation, only two dilution rates were chosen as a platform for evaluating $\mathrm{H}_{2}$ production efficiency and analyzing the population dynamics, i.e., 0.06 and $0.15 \mathrm{~h}^{-1}$. No residual glucose or xylose could be detected at steady state of $D=0.06 \mathrm{~h}^{-1}$, confirming that the co-culture was carbon limited (Table 3 ). $\mathrm{H}_{2}$ yield decreased with the dilution rate and was comparable to that obtained under non-carbon limitation at the two steady states evaluated. $\mathrm{H}_{2}$ production rate followed an opposite trend, since it increased with the dilution rate, as was seen under noncarbon limitation. Product yields and sugar consumption and metabolite formation rates as well as carbon and electron recoveries at the two dilution rates are detailed in Additional file 2 (Tables S3.1 and S3.2). 
Table $2 \mathrm{H}_{2}$ production and biomass formation by the co-culture on a mixture of glucose $\left(5 \mathrm{~g} \mathrm{~L}^{-1} ; 27.8 \mathrm{mM}^{2}\right.$ and xylose $\left(5 \mathrm{~g} \mathrm{~L}^{-1} ; 33.3 \mathrm{mM}\right)$ at steady states of different dilution rates (yeast extract, $1 \mathrm{~g} \mathrm{~L}^{-1} ; \mathrm{pH} 6.7 ; 70^{\circ} \mathrm{C}$ )

\begin{tabular}{|c|c|c|c|c|c|c|c|}
\hline \multirow[t]{2}{*}{$D\left(\mathrm{~h}^{-1}\right)$} & \multirow{2}{*}{$\begin{array}{l}Y_{\mathrm{H}_{2}}[\mathrm{~mol} \\
\left.\left(\mathrm{mol}^{\mathrm{C}}\right)^{-1}\right]\end{array}$} & \multirow{2}{*}{$\mathrm{Q}_{\mathrm{H}_{2}}{ }_{\left(\mathrm{mmol} \mathrm{L}^{-1} \mathrm{~h}^{-1}\right)}$} & \multirow{2}{*}{$q_{\left(\mathrm{Hmol}_{2}\right.} g_{\left.\mathrm{gCDW}^{-1} \mathrm{~h}^{-1}\right)}$} & \multirow{2}{*}{ 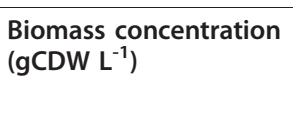 } & \multirow{2}{*}{$\begin{array}{l}Y_{\mathrm{sx}} \\
{\left[\mathrm{gCDW}(\mathrm{mol} \mathrm{C6})^{-1}\right]}\end{array}$} & \multicolumn{2}{|c|}{ Residual sugar (mM) } \\
\hline & & & & & & Glucose & Xylose \\
\hline 0.04 & 3.5 & 3.8 & 12.7 & 0.30 & 11.1 & 18.4 & 8.4 \\
\hline 0.06 & 3.6 & 4.3 & 14.2 & 0.30 & 14.9 & 18.9 & 12.0 \\
\hline 0.08 & 3.5 & 6.2 & 15.5 & 0.40 & 18.0 & 19.0 & 9.3 \\
\hline 0.12 & 3.1 & 8.3 & 15.0 & 0.55 & 24.4 & 21.4 & 12.1 \\
\hline 0.15 & 2.9 & 10.3 & 18.4 & 0.56 & 23.6 & 21.0 & 12.4 \\
\hline 0.2 & 2.8 & 11.0 & 18.3 & 0.60 & 30.7 & 22.7 & 15.2 \\
\hline 0.25 & 2.9 & 11.6 & 21.0 & 0.55 & 34.6 & 24.2 & 17.8 \\
\hline 0.3 & 2.5 & 11.6 & 21.0 & 0.55 & 36.1 & 23.9 & 19.0 \\
\hline
\end{tabular}

The steady-state residual sugar concentration increased by increasing $D$ (Table 3), while the overall steady-state biomass concentration decreased from 0.44 $\pm 0.03 \mathrm{gCDW} \mathrm{L}^{-1}$ at $0.06 \mathrm{~h}^{-1}$ to $0.35 \pm 0.03 \mathrm{gCDW} \mathrm{L}^{-1}$ at $0.15 \mathrm{~h}^{-1}$, which might indicate that the culture was approaching its critical $D$. Although the co-culture was carbon limited, neither C. saccharolyticus nor C. kristjanssonii washed out, as revealed by qPCR analysis (Figure 2). C. kristjanssonii cells constituted around 85\% of the total population at the onset of starting the continuous cultivation mode, whereas its steady-state relative cell count went below $10 \%$ at $D=0.06 \mathrm{~h}^{-1}$. The organism, however, restored its predominance when $D$ was increased to $0.15 \mathrm{~h}^{-1}$, depicting its behaviour under non-carbon limitation.

\section{Competition for one growth-limiting substrate}

The ability of C. saccharolyticus and C. kristjanssonii to stably coexist under chemostat conditions was further challenged by growing the co-culture on only one sugar, as the growth-limiting substrate, at a time. Glucose was added to the feed at a concentration of $4 \mathrm{~g} \mathrm{~L}^{-1}$, and the performance of the co-culture was also compared to that of the individual species under the same conditions. Glucose was almost completely depleted at both dilution rates by the co-culture and by the pure culture of

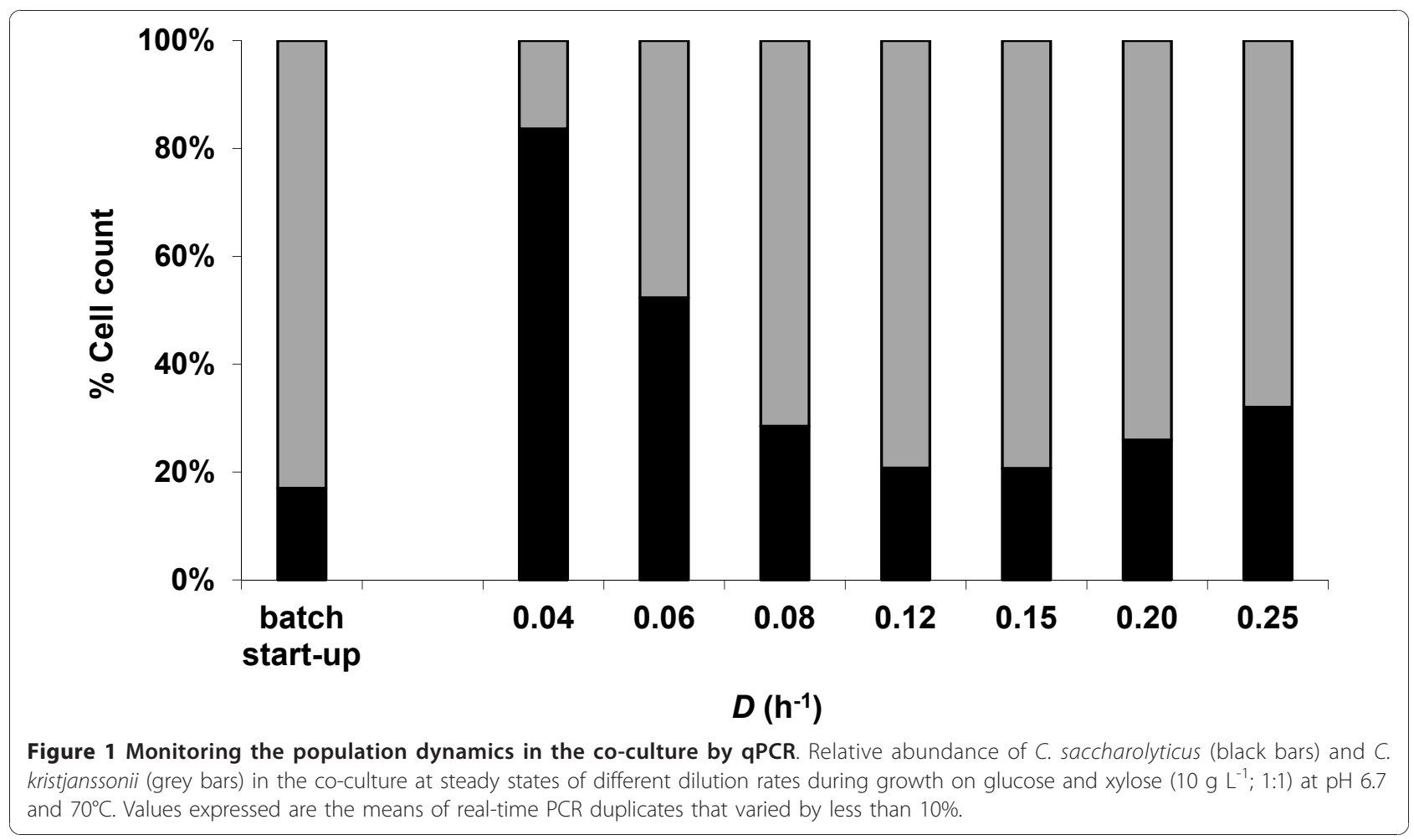


Table 3 Performance of the co-culture in a carbon-limited chemostat at steady states of two different dilution rates with glucose and xylose $\left(4 \mathrm{~g} \mathrm{~L}^{-1} ; 1: 1\right)$ as the growth limiting substrates (yeast extract, $1 \mathrm{~g} \mathrm{~L}^{-1} ; \mathrm{pH}^{4} .7 ; 70^{\circ} \mathrm{C}$ )

\begin{tabular}{|c|c|c|c|c|c|c|c|}
\hline \multirow{2}{*}{$\begin{array}{l}D \\
\left(\mathrm{~h}^{-1}\right)\end{array}$} & \multirow{2}{*}{$\begin{array}{l}Y_{\mathrm{H}_{2}}[\mathrm{~mol} \\
\left(\mathrm{mol}^{-1} \mathrm{C6}^{-1}\right]\end{array}$} & \multirow{2}{*}{$\begin{array}{l}Q_{\mathrm{H}_{2}} \\
\left(\mathrm{mmol} \mathrm{L}^{-1} \mathrm{~h}^{-1}\right)\end{array}$} & \multirow{2}{*}{$\underset{\left(\mathrm{mmol}_{2} \mathrm{gCDW}^{-1} \mathrm{~h}^{-1}\right)}{q_{\mathrm{H}_{2}}}$} & \multirow{2}{*}{$\begin{array}{l}\text { Biomass concentration } \\
\left(\mathrm{gCDW} \mathrm{L} \mathrm{L}^{-1}\right)\end{array}$} & \multirow{2}{*}{$\begin{array}{l}Y_{\mathrm{sx}} \\
{\left[\mathrm{gCDW}(\mathrm{mol} \mathrm{C6})^{-1}\right]}\end{array}$} & \multicolumn{2}{|c|}{ Residual sugar (mM) } \\
\hline & & & & & & Glucose & Xylose \\
\hline 0.06 & $3.6 \pm 0.1$ & $4.5 \pm 0.2$ & $10.2 \pm 0.3$ & $0.44 \pm 0.03$ & $21.0 \pm 0.9$ & 0 & 0 \\
\hline 0.15 & $3.2 \pm 0$ & $8.6 \pm 0.4$ & $24.7 \pm 1.1$ & $0.35 \pm 0.03$ & $19.4 \pm 1.0$ & $1.7 \pm 0.1$ & $1.4 \pm 0.1$ \\
\hline
\end{tabular}

Values are means of two independent replicates \pm standard deviation.

C. kristjanssonii (Table 4). In pure culture of C. saccharolyticus, a residual steady-state glucose concentration of $8.6 \pm 0.6 \mathrm{mM}$ was detected in the effluent by increasing $D$ from 0.06 to $0.15 \mathrm{~h}^{-1}$, with a concomitant decrease in biomass concentration. The $\mathrm{H}_{2}$ yields obtained by the co-culture were higher than the corresponding yields obtained by either species in pure culture at both dilution rates. The highest volumetric $\mathrm{H}_{2}$ production rate was achieved in C. kristjanssonii pure culture and in its co-culture with $C$. saccharolyticus at $D=0.15 \mathrm{~h}^{-1}$, whereas the highest specific $\mathrm{H}_{2}$ production rate was solely achieved by the former culture at the same $D$ (Table 4). A thorough comparison of product distribution in the pure culture of each strain and in the coculture as well as carbon and electron recoveries can be found in Additional file 2 (Tables S4.1 and S4.2).

Interestingly, both organisms coexisted in the system despite the culture being truly limited for one carbon source, i.e., glucose. C. kristjanssonii was the predominant species in the co-culture during the batch start-up

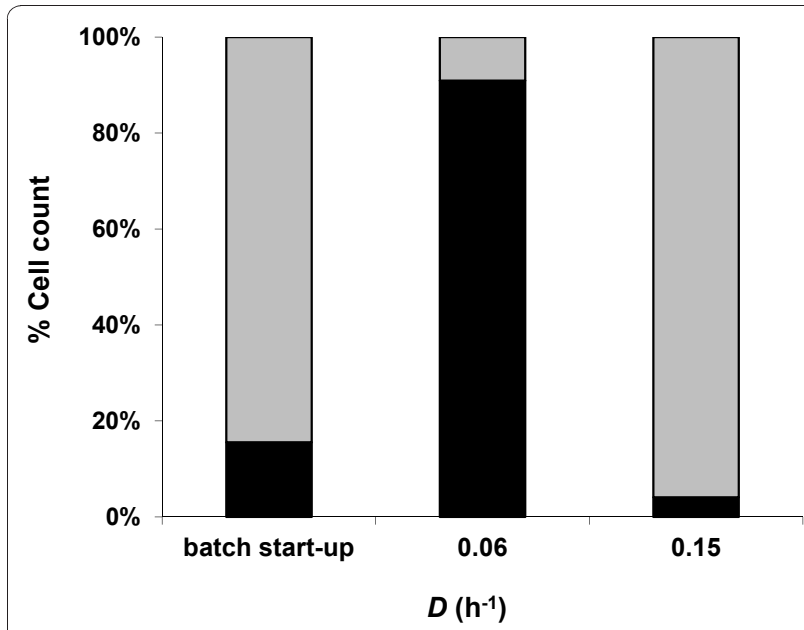

Figure 2 Relative abundance of $C$. saccharolyticus (black bars) and C. kristjanssonii (grey bars) in the co-culture on glucose and xylose $\left(4 \mathrm{~g} \mathrm{~L}^{-1} ; 1: 1\right)$ at $\mathrm{pH} 6.7$ and $70^{\circ} \mathrm{C}$ at the end of the batch start-up phase and during steady state growth at two different dilution rates. Values expressed are the means of realtime PCR duplicates that varied by less than $10 \%$. The figure is a representative of the population dynamics in two independent chemostat cultures. phase and at the higher $D$ (Figure 3), underlining a similar pattern to that obtained during co-fermentation of glucose and xylose. It is noteworthy that a similar pattern of population dynamics was also obtained with an opposite sequence of dilution rates of this experiment, where a steady state was achieved first at $D=0.15 \mathrm{~h}^{-1}$ and then at $D=0.05 \mathrm{~h}^{-1}$ (data not shown).

Unlike glucose, xylose could not be completely utilized by the co-culture at either dilution rate when it was used as the sole sugar in the feed at $4 \mathrm{~g} \mathrm{~L}^{-1}(26.7 \mathrm{mM}$; Table 5). The reason for that is unclear since xylose appears to be the preferable sugar during co-fermentation with glucose (cf., Table 2). By increasing $D$, more xylose was consumed and steady-state biomass concentration has almost doubled. $\mathrm{H}_{2}$ yield of the co-culture on xylose did not appear to vary with the dilution rate, and was lower than that obtained on glucose. Specific $\mathrm{H}_{2}$ production rate, however, followed an opposite trend, since it was significantly higher on xylose at both dilution rates. The same applies for the specific production rates of all other fermentation products (see Additional file 2: Table S5.1), which could be attributed to the low biomass concentration obtained on xylose.

The remarkable ability of $C$. saccharolyticus and C. kristjanssonii to stably co-exist was retained during growth on xylose. Although C. saccharolyticus cells constituted less than $5 \%$ of the total population in the coculture during the batch start-up phase, the organism could outgrow $C$. kristjanssonii in the co-culture at steady state of $D=0.06 \mathrm{~h}^{-1}$ (Figure 4 ), as was seen on glucose and on glucose and xylose mixture. The relative abundance of C. kristjanssonii in the co-culture on xylose at the end of the batch start-up phase and at both dilution rates matched the behaviour of the organism in all other fermentations.

\section{Capturing the population dynamics in the co-culture in silico}

It was previously reported that C. kristjanssonii exhibits a lower maximum specific growth rate than that of C. saccharolyticus during batch growth on glucose and xylose [28]. The consistent predominance of C. kristjanssonii in the co-culture during batch growth and at higher $D$ under all conditions tested in this study 
Table 4 Comparison of steady-state $\mathrm{H}_{2}$ and biomass production by $C$. saccharolyticus, $C$. kristjanssonii and their co-

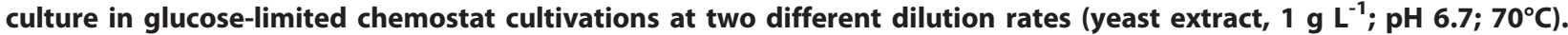

\begin{tabular}{|c|c|c|c|c|c|c|c|}
\hline Organism(s) & $D\left(\mathrm{~h}^{-1}\right)$ & $\begin{array}{l}Y_{\mathrm{H}^{\prime}}[\mathrm{mol} \\
\left(\mathrm{mol} \mathrm{C6}^{-1}\right]\end{array}$ & $\underset{\left.\mathrm{L}^{-1} \mathrm{~h}^{2-1}\right)}{\mathrm{Q}_{\mathrm{H}^{2}}}(\mathrm{mmol}$ & $\begin{array}{l}q_{\mathrm{H}_{2}}(\mathrm{mmol} \\
\left.\mathrm{gCDW}^{-1} \mathrm{~h}^{-1}\right)\end{array}$ & $\begin{array}{l}\text { Biomass concentration } \\
\left(\mathrm{gCDW} \mathrm{L}^{-1}\right)\end{array}$ & $\begin{array}{l}Y_{\mathrm{sx}}[\mathrm{gCDW} \\
\left.(\mathrm{mol} \mathrm{C6})^{-1}\right]\end{array}$ & $\begin{array}{l}\text { Residual glucose } \\
(\mathrm{mM})\end{array}$ \\
\hline \multirow[t]{2}{*}{ C. saccharolyticus } & 0.06 & $3.5 \pm 0.1$ & $4.9 \pm 0.14$ & $13.2 \pm 0.1$ & $0.38 \pm 0.01$ & $15.8 \pm 0.2$ & 0 \\
\hline & 0.15 & $3.1 \pm 0.2$ & $7 \pm 0.3$ & $24.4 \pm 1$ & $0.29 \pm 0.03$ & $19.3 \pm 1.1$ & $8.6 \pm 0.6$ \\
\hline \multirow[t]{2}{*}{ C. kristjanssonii } & 0.06 & $3.5 \pm 0.1$ & $4.8 \pm 0.1$ & $17.8 \pm 0.5$ & $0.27 \pm 0.01$ & $11.7 \pm 0.0$ & 0 \\
\hline & 0.15 & $3.0 \pm 0.1$ & $10.3 \pm 0.16$ & $34.6 \pm 1.6$ & $0.3 \pm 0.02$ & $13.0 \pm 0.1$ & $0.2 \pm 0.0$ \\
\hline \multirow[t]{2}{*}{ Co-culture } & 0.06 & $3.7 \pm 0.0$ & $4.8 \pm 0.2$ & $14.8 \pm 0.8$ & $0.33 \pm 0.03$ & $15.4 \pm 0.8$ & 0 \\
\hline & 0.15 & $3.5 \pm 0.0$ & $10.4 \pm 0.14$ & $21.4 \pm 0.8$ & $0.49 \pm 0.01$ & $24.6 \pm 0.8$ & 0 \\
\hline
\end{tabular}

Values are means of two independent replicates \pm standard deviation.

alluded to the possibility of the growth of the organism being enhanced by one or more compounds released by C. saccharolyticus. Such an interaction could be a possible reason behind the stable coexistence of the two strains even in the presence of only one growth-limiting substrate. For testing this hypothesis, a mathematical model based on ordinary differential equations for a continuous culture system was extended with equations describing the enhancement of biomass yield and the maximum specific growth rate of $C$. kristjanssonii by a proposed compound released by $C$. saccharolyticus (see Materials and Methods section). Indeed, the model was able to mimic the population dynamics in the co-culture on glucose (Figure 5), provided that well-estimated values of the parameters were used (see Additional file 1: Table S1). Testing the model, it revealed that enhancing the maximum specific growth rate was the most

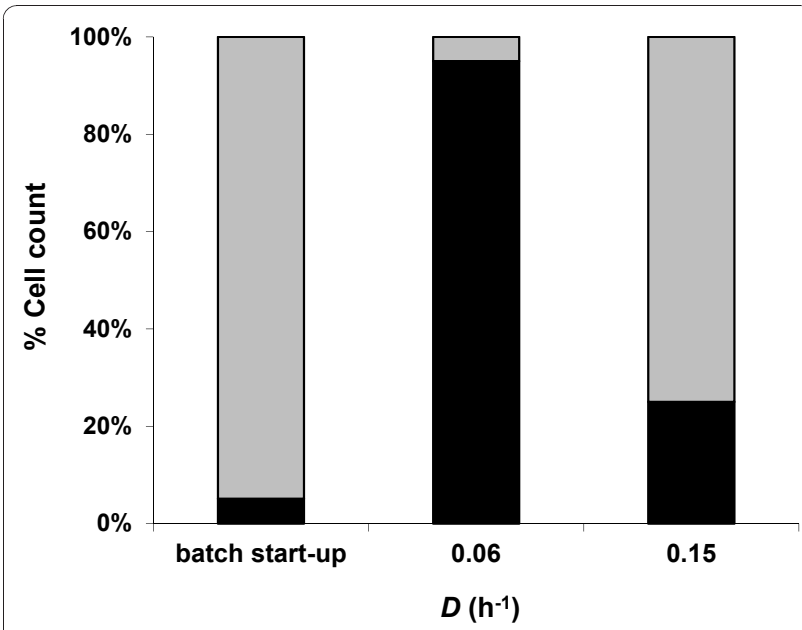

Figure 3 Relative abundance of $C$. saccharolyticus (black bars) and $C$. kristjanssonii (grey bars) in the co-culture in a glucoselimited chemostat culture at $\mathrm{pH} 6.7$ and $70^{\circ} \mathrm{C}$ at the end of the batch start-up phase and during steady state growth at two different dilution rates. Values expressed are the means of realtime PCR duplicates that did vary by less than $10 \%$. The figure is a representative of the population dynamics in two independent chemostat cultures. profound effect, i.e., in the absence of any enhancing effect on this variable C. kristjanssonii would have washed out at all D's (data not shown). A lack of the stimulatory effect on the biomass yield of C. kristjanssonii would have made C. saccharolyticus dominant at all times, but the former would have remained in the system (data not shown). According to the model, at higher $D$ (i.e., $0.15 \mathrm{~h}^{-1}$ ) a true steady state is attained after ca. 15 volume changes, whereas at a lower $D$ (i.e., $0.06 \mathrm{~h}^{-1}$ ) it will be reached after ca. 50 volume changes. In practice, however, sampling after 18 and 9 volume changes from the cultures at a $D$ of 0.15 and $0.06 \mathrm{~h}^{-1}$, respectively, indicated that a steady state has been attained. This difference between the experimentally determined and model-predicted number of volume changes could be a result of non-optimum values of any of the model parameters for which no experimental data were available (Additional file 1). Extending the in silico simulation beyond $1000 \mathrm{~h}$ revealed that C. kristjanssonii never washed out at either $D$ (data not shown).

Effect of C. saccharolyticus culture supernatant on growth of C. kristjanssonii

The outcome of the in silico simulations provoked our interest to confirm the presence of any secretory products of $C$. saccharolyticus that could enhance the growth of $C$. kristjanssonii. For this, a total inoculum volume of C. kristjanssonii of $15 \%(\mathrm{v} / \mathrm{v})$, in which one third of the liquid phase was replaced by C. saccharolyticus cell-free, spent-culture broth, was used to initiate a batch culture on glucose $\left(10 \mathrm{~g} \mathrm{~L}^{-1}\right)$. As illustrated in Figure 6, the pure culture of $C$. kristjanssonii supplemented with $C$. saccharolyticus cell-free growth supernatant had, indeed, a shorter lag phase than a control culture that lacked C. saccharolyticus culture supernatant. Moreover, the treated culture exhibited around $18 \%$ higher maximum biomass concentration, which corresponds to an increase in CDW by $0.16 \mathrm{~g} \mathrm{~L}^{-1}$. No significant change in the maximum specific growth rate of C. kristjanssonii, however, was observed in the treated culture. To further amplify the possible growth- 
Table 5 Steady-state $\mathrm{H}_{2}$ and biomass production by the co-culture on xylose $\left(4 \mathrm{~g} \mathrm{~L}^{-1}\right)$ in the presence of yeast extract $\left(1 \mathrm{~g} \mathrm{~L}^{-1}\right)$ at two different dilution rates $\left(\mathrm{pH} 6.7 ; 70^{\circ} \mathrm{C}\right)$

\begin{tabular}{lllllll}
\hline$D\left(\mathbf{h}^{-1}\right)$ & $\begin{array}{l}Y_{\mathrm{H}_{2}}[\mathrm{~mol} \\
\left.\left(\mathrm{mol}^{-1} \mathrm{C6}\right)^{-1}\right]\end{array}$ & $\begin{array}{l}Q_{\mathrm{H}_{2}} \\
\left(\mathrm{mmol} \mathrm{L}^{-1} \mathbf{h}^{-1}\right)\end{array}$ & $\begin{array}{l}q_{\mathrm{H}_{2}} \\
\left(\mathrm{mmol} \mathrm{gCDW}^{-1} \mathbf{h}^{-1}\right)\end{array}$ & $\begin{array}{l}\text { Biomass concentration } \\
\left(\mathbf{g C D W ~ L}^{-1}\right)\end{array}$ & $\begin{array}{l}Y_{\text {sx }} \text { [gCDW } \\
\left.(\mathrm{mol} \mathrm{C6})^{-1}\right]\end{array}$ & $\begin{array}{l}\text { Residual xylose } \\
\left(\mathrm{mM}^{2}\right)\end{array}$ \\
0.06 & $2.7 \pm 0.1$ & $3.0 \pm 0.2$ & $22.6 \pm 4.1$ & $0.13 \pm 0.04$ & $7.4 \pm 1.7$ & $6.9 \pm 0.9$ \\
0.15 & $2.7 \pm 0.0$ & $8.5 \pm 0.2$ & $33.0 \pm 8.9$ & $0.27 \pm 0.08$ & $13.0 \pm 3.7$ & $3.7 \pm 1.4$ \\
\hline
\end{tabular}

Values are means of two independent replicates \pm standard deviation.

enhancing effect, a lower inoculum volume of $C$. kristjanssonii was used, i.e., $10 \%$, in which $50 \%$ of the liquid phase was replaced by $C$. saccharolyticus cell-free growth supernatant. Under this condition, the treated culture exhibited a lag phase of only $5 \mathrm{~h}$, compared to $54 \mathrm{~h}$ in the control (data not shown).

\section{Discussion}

Hydrogen-producing co-cultures constructed de novo may offer a better performance than mixed-population enrichments, while overcoming some of the limitations of pure cultures based on synergies among the microorganisms involved. In several previous studies on defined co-cultures, it was a common strategy to proceed by isolating the dominant members of a mixed enrichment culture and then recombining the isolates in order to reproduce the stability and function of the original microflora $[17,21,29,30]$. Here, we combined two closely-related strains from geographically distant, albeit similar, habitats, i.e., C. saccharolyticus DSM 8903 and C. kristjanssonii DSM 12137. The former bacterium was isolated from a thermal pool in New Zealand [31,32], whereas the latter was isolated from a biomat sample of

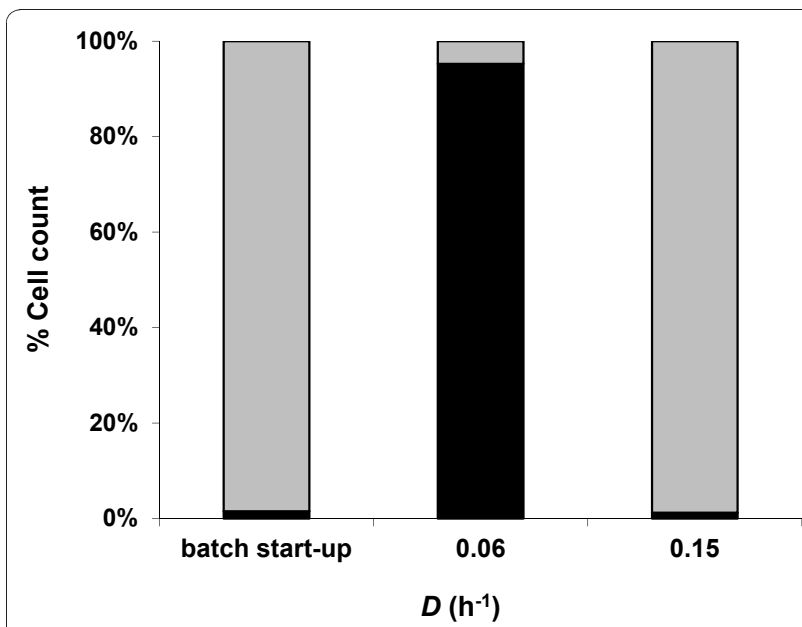

Figure 4 Relative abundance of $C$. saccharolyticus (black bars) and C. kristjanssonii (grey bars) in the co-culture on xylose $(4 \mathrm{~g}$ $\mathrm{L}^{-1}$ ) at $\mathrm{pH} 6.7$ and $70^{\circ} \mathrm{C}$ at the end of the batch start-up phase and during steady state growth at two different dilution rates Values expressed are the means of real-time PCR duplicates that varied by less than $10 \%$. The figure is a representative of the population dynamics in two independent chemostat cultures. an Icelandic hot spring [33]. Both organisms are strictly anaerobic, extreme thermophilic heterotrophs with the ability to degrade complex polysaccharides and ferment both hexose and pentose sugars [28,31,33,34].

A CSTR seeded with C. saccharolyticus and C. kristjanssonii could be successfully operated over a period of 70 days at different dilution rates with both species coexisting in the system, when glucose and xylose (10 g $\mathrm{L}^{-1}$ ) were used as the main carbon and energy sources. According to steady-state residual sugar analysis, the culture was carbon-sufficient at all dilution rates, indicating that another nutrient must have been limiting the growth. Based on the standard biomass formula, i.e., $\mathrm{CH}_{1.8} \mathrm{O}_{0.5} \mathrm{~N}_{0.2}$ [35], and the maximum biomass concentration obtained by either organism in batch fermentations (ca. 1 gCDW L ${ }^{-1}$ ), the amount of inorganic nitrogen in the feed, present as $\mathrm{NH}_{4} \mathrm{Cl}$, is considered to be in excess. A component in yeast extract (YE), e.g., a growth factor, is most likely to be responsible for growth limitation and incomplete sugar utilization by the co-culture, since the YE-to-sugar ratio in the feed was only $1 / 10$. This kind of limitation has been previously suggested for C. saccharolyticus [36] and for Thermoanaerobacter ethanolicus [37] during continuous fermentation of glucose and xylose, respectively. In our study, this was verified by increasing the YE-to-sugar ratio in the feed to $1 / 4$, where the co-culture could be carbon limited when grown on a mixture of glucose and xylose (Table 3 ) or glucose only (Table 4).

In general, the $\mathrm{H}_{2}$ yields obtained in C. saccharolyticusC. kristjanssonii co-cultures in this study under both carbon and non-carbon limited conditions are significantly higher than the yields previously reported for defined cocultures [29,38-40] or mixed-culture enrichments $[3,23,41]$, regardless of the type of reactor employed. The decrease in $\mathrm{H}_{2}$ yield with the dilution rate observed in the co-culture fermentations as well as in the pure cultures of C. saccharolyticus and C. kristjanssonii was, in part, a result of increased lactate formation (see Additional file 2), which drains some of the electrons required for $\mathrm{H}_{2}$ production. The highest $\mathrm{H}_{2}$ yield of the co-culture was 3.7 mol per mol of hexose sugar (i.e., $92.5 \%$ of the maximum theoretical $\mathrm{H}_{2}$ yield that can be achieved via dark fermentation). This yield could only be achieved by limiting the co-culture on glucose at low $D$ (i.e., $0.06 \mathrm{~h}^{-1}$ ) and was higher than that obtained by either organism in pure 

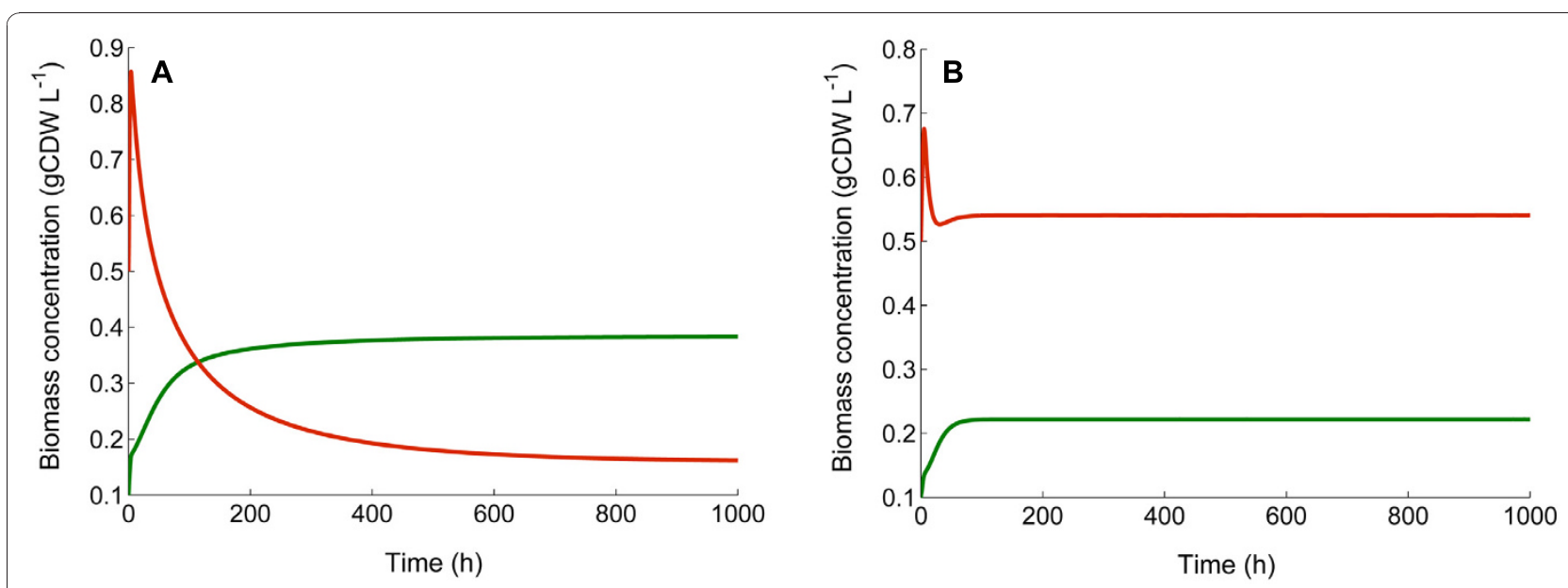

Figure 5 In silico glucose-limited chemostat cultivations. Simulation of the population dynamics in the co-culture on glucose $\left(4 \mathrm{~g} \mathrm{~L}^{-1}\right)$ in chemostat cultures at $D$ of $0.06 \mathrm{~h}^{-1}(\mathrm{~A})$, and $D$ of $0.15 \mathrm{~h}^{-1}$ (B), using the developed mathematical model. Green lines represent $C$. saccharolyticus and red lines represent C. kristjanssonii.

culture under the same experimental conditions (Table 4), alluding to a possible synergistic effect of the two strains on $\mathrm{H}_{2}$ production. This also indicates that carbon limitation can be a successful strategy for improving the sugar-

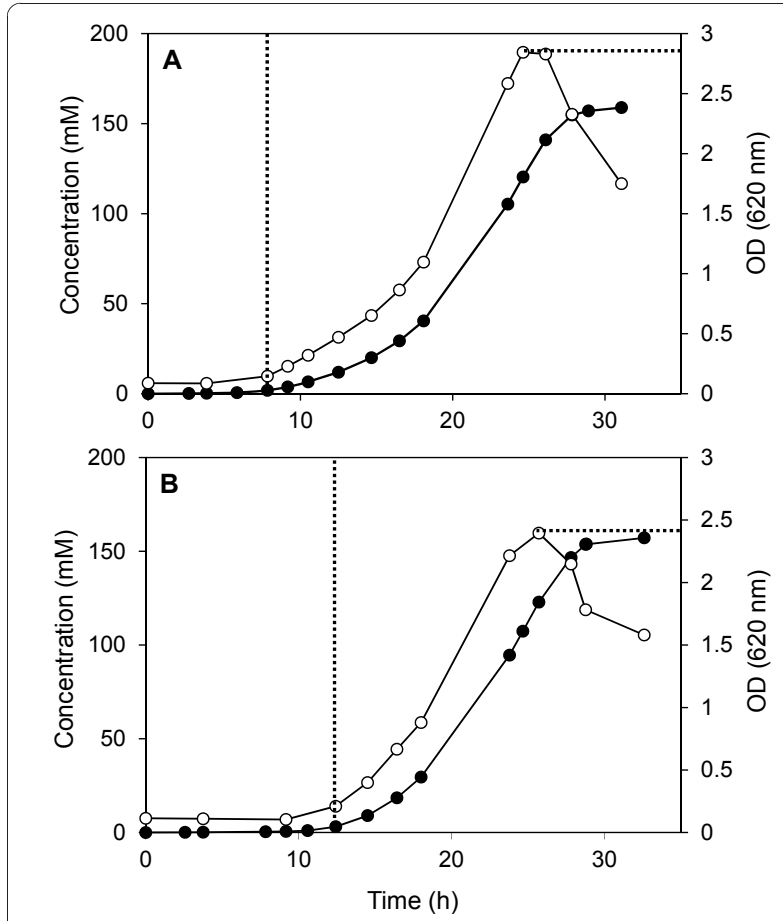

Figure 6 Effect of $C$. saccharolyticus growth supernatant on C. kristjanssonii. Comparison of log phase and maximum biomass concentration of $C$. kristjanssonii on glucose $\left(10 \mathrm{~g} \mathrm{~L}^{-1}\right)$ at $\mathrm{pH} 6.7$ and $70^{\circ} \mathrm{C}$ in batch mode in the presence (A) and absence (B) of $C$. saccharolyticus cell-free growth supernatant. Symbols: "O", biomass $\left(O D_{620}\right) ; " \bullet "$ ", accumulative $\mathrm{H}_{2}$. The experiment is a representative of two independent replicates. conversion efficiency and increasing $\mathrm{H}_{2}$ yield of the coculture. Although it remains unclear why limiting the cells for glucose leads to what appears to be more efficient substrate utilization and increased $\mathrm{H}_{2}$ production, Bisaillon et al [42] suggested the possibility of carbon flow to secondary metabolic pathways, for example, glycogen synthesis, being restricted at low glucose concentrations thereby shunting most of the carbon to the catabolic, $\mathrm{H}_{2}$-generating, pathways.

In contrast to $\mathrm{H}_{2}$ yield, the volumetric $\mathrm{H}_{2}$ production rate of the co-culture constructed in this study increased by increasing the dilution rate, which agrees with data from previous reports on fermentative $\mathrm{H}_{2}$ production in chemostat cultures [36,43]. The maximum $\mathrm{H}_{2}$ production rate achieved by the co-culture at the highest $D$ tested in this study (Table 2) is equivalent to $0.28 \mathrm{~L}_{\mathrm{H} 2}$ $\mathrm{L}_{\text {culture }}{ }^{-1} \mathrm{~h}^{-1}$, which lies within the upper range of previously reported productivities of mixed culturefermentations in CSTRs [41,44-46]. The optimum balance between yield and productivity was observed under glucose limitation at steady state of the higher $D$ (Table 4), implying that both carbon limitation and the dilution rate are critical factors for optimizing $\mathrm{H}_{2}$-production efficiency by the co-culture. Under those conditions, the volumetric $\mathrm{H}_{2}$ production rate of the co-culture was equivalent to that of $C$. kristjanssonii, which indeed was the predominant organism in the co-culture. $\mathrm{H}_{2}$ yield, however, was significantly higher than that of $\mathrm{C}$. kristjanssonii, pointing again at a possible synergistic effect of the two strains on $\mathrm{H}_{2}$ production.

An interesting outcome of the present study is the ability of the two closely related Caldicellulosiruptor species to stably coexist over the whole range of conditions tested. Since both species occupy the same trophic 
level [31,33], they are expected to compete for the same growth-limiting substrate in a chemostat culture. Based on the competitive exclusion principle [47], this competition should result in one strain in the co-culture completely displacing the other in the development towards a steady state under a given condition. Since YE, which is a complex nutrient, was suspected for growth limitation in the co-culture under carbon-sufficient conditions, the coexistence could be explained in that each species was limited on a different component in YE. However, the stable coexistence of the two strains observed at steady-state conditions with glucose as the sole growth-limiting substrate cannot be explained on that basis. As discussed below, the reproducible pattern of population dynamics observed under different conditions in the present study provides a clue on the occurrence of interspecies interaction in the co-culture, which could be the reason behind the stable coexistence of C. saccharolyticus and C. kristjanssonii.

The prevalence of an organism in a batch culture depends on its maximum specific growth rate compared with that of the other organisms capable of growth in the inoculum [2]. Since C. kristjanssonii exhibits a $40 \%$ lower maximum specific growth rate than that of C. saccharolyticus during batch growth on glucose and xylose [28], the prevalence of the former in their co-culture during the batch start-up phase and at higher dilution rates implies that it acquires a higher specific growth rate in presence of the latter. In addition, the biomass yield of the C. kristjanssonii-dominated co-culture in glucose-limited chemostat cultivations at a $D$ of $0.15 \mathrm{~h}^{-1}$ was significantly higher than that of $C$. kristjanssonii alone under otherwise the same conditions (Table 4), which points to an enhancing effect of $C$. saccharolyticus on the biomass yield of C. kristjanssonii. Indeed, the fact that none of the strains was completely displaced by the other at any of the steady states evaluated supports the hypothesis of the occurrence of a beneficial sort of interspecies interaction in the co-culture rather than only competition for the same growth-limiting nutrient. The simple mathematical model we developed to describe this proposed interaction, in terms of compound $E$ that has a growth-enhancing effect on C. kristjanssonii, could successfully mimic the stable coexistence and predict the population dynamics in the co-culture, ruling out any other required mechanisms (Figure 5). Furthermore, it is the combination of enhancing the growth rate and biomass yield of C. kristjanssonii that creates the condition for stable coexistence as observed in the chemostat-cultivations. This condition only remains valid as long as $C$. saccharomyces stays in the system to provide the proposed growthenhancing compound. The reduction in the lag phase and the increase in maximum biomass concentration of C. kristjanssonii in the presence of C. saccharolyticus growth supernatant (Figure 6) provided experimental evidence on the presence of such a compound or signaling molecule that can enhance the growth of C. kristjanssonii. Although the maximum specific growth rate was not affected under these conditions, this could be due to the absence of C. saccharolyticus cells in the reactor, thus preventing the continuous supply of the growth-enhancing compound. It cannot also be ruled out that this compound is actually a product of cell lysis rather than a secretory product since $C$. saccharolyticus cells are prone to lyse significantly $[48,49]$.

In light of the social evolution theory of microorganisms [50], the ability of C. saccharolyticus to enhance the growth of $C$. kristjanssonii might be classified as an altruistic cooperation. An explanation for altruistic cooperation between close relatives is best provided by the kin selection theory, where an individual species can still pass on its own genes to the next generation indirectly by helping a closely related species to reproduce. Unraveling the precise mechanism of this interaction or the nature of the involved molecules, however, remains a conceptual and methodological challenge.

It is well known that each population or individual detects and responds to the presence of others in a consortium by trading metabolites or by exchanging dedicated molecular signals [1,51]. Growth enhancement as a consequence of interspecies interactions in bacteria may occur in response to some signaling molecules [52]. Processed oligopeptides are known quorum sensing molecules, or autoinducers, that are used by Gram-positive bacteria for communication [53]. Nichols et al [54] presented evidence that short peptides may be essential factors for initiating growth of 'uncultivable' cells. The existence of a peptide-based quorum sensing in hyperthermophilic bacteria was also previously demonstrated in a co-culture of Thermotoga maritima and Methanococcus jannaschii and was responsible for inducing exopolysaccharide production and enhancing biofilm formation by the former organism [13]. Moreover, it has been recently suggested that the addition of a second microbe, viz. Tm. maritima, to a pure culture of C. saccharolyticus triggers events causing the presence, absence and differential expression of protein species within the system [15]. Although the genome of C. saccharolyticus has been fully sequenced and annotated [34], it is difficult to examine for the presence of putative small peptide signaling molecules since signaling peptides are often products of genes encoding proteins less than 100 amino acids in length. In C. saccharolyticus genome, there are 496 of such genes, around 55\% of which encode for hypothetical proteins (NCBI Entrez; http://www.ncbi.nlm.nih.gov/sites/entrez).

While genomic information did not prove useful, other approaches, such as microarray-based functional 
genomics approaches $[12,14]$ or bioassay-directed fractionation and analysis of the growth supernatant [54], can be adopted for the identification of candidate signaling molecules and understanding the molecular mechanisms behind the interactions in the co-culture. This is, however, beyond the scope of the current study and may become more feasible by the availability of the complete genome sequence of C. kristjanssonii.

\section{Conclusions}

The present study provides essential evidence on the possibility of stable co-existence of two closely related bacteria isolated from distant habitats in a continuousflow system under steady-state conditions. This augments the suggestion of de novo constructed or 'designer' co-cultures as potential alternatives for several biotechnological applications that are, otherwise, carried out using mixed culture enrichments. Although the increase in $\mathrm{H}_{2}$ yield by the co-culture constructed in this study was not dramatic, as compared with that of the individual strains, it is still higher than the $\mathrm{H}_{2}$ yield reported for any mixed culture to date. Generally, benefits of the use of the co-culture other than improving product yield may include enhanced resistance to invasion by other species and increased chance of biofilm formation [55]; the latter being a desirable feature in several industrial fermentation systems. Extending the range of substrate utilization is another advantage that can be gained by combining C. saccharolyticus and C. kristjanssonii in a co-culture. For example, C. saccharolyticus ferments L-arabinose and L-rhamnose, whereas C. kristjanssonii does not grow on these sugars [33] and probably the latter would be able to utilize some substrates not readily consumed by the former, which merits further investigation.

\section{Additional material}

Additional file 1: Values of different parameters included in the coculture model.

Additional file 2: Fermentation details of different chemostat cultivations. Product yields, specific rates of substrate consumption and metabolite formation and carbon and electron recoveries in different chemostat cultivations of C. saccharolyticus, C. kristjanssonii and/or their co-culture (8 tables)

\section{Acknowledgements \\ AAZ acknowledges support from the Ministry of Higher Education in Egypt and the Swedish Energy Agency (Energimyndigheten; nr. 31090-1). This study was financially supported by the Commission of European Communities, Sixth Framework Program, Priority 6, Sustainable Energy Systems (019825 HYVOLUTION).}

\section{Authors' contributions}

AAZ conceived of the study, designed and performed the experimental and computational work and drafted the manuscript. PR participated in the design of the PCR assays and critically revised the manuscript. EWJN developed the mathematical model, participated in interpreting the experimental results and critically revised the manuscript. All authors read and approved the final manuscript.

\section{Competing interests}

The authors declare that they have no competing interests.

Received: 28 November 2010 Accepted: 30 December 2010 Published: 30 December 2010

\section{References}

1. Brenner K, You LC, Arnold FH: Engineering microbial consortia: a new frontier in synthetic biology. Trends Biotechnol 2008, 26:483-489.

2. Stanbury PF, Whitaker A, Hall SJ: Principles of Fermentation Technology. 2 edition. Butterworth Heinemann, Oxford; 2000.

3. Kleerebezem R, van Loosdrecht MCM: Mixed culture biotechnology for bioenergy production. Curr Opin Biotechnol 2007, 18:207-212.

4. Weibel DB: Building communities one bacterium at a time. Proc Natl Acad Sci USA 2008, 105:18075-18076.

5. Sieuwerts S, de Bok FA, Hugenholtz J, van Hylckama Vlieg JE: Unraveling microbial interactions in food fermentations: from classical to genomics approaches. Appl Environ Microbiol 2008, 74:4997-5007.

6. Pfeiler EA, Klaenhammer TR: The genomics of lactic acid bacteria. Trends Microbiol 2007, 15:546-553

7. Fu N, Peiris P, Markham J, Bavor J: A novel co-culture process with Zymomonas mobilis and Pichia stipitis for efficient ethanol production on glucose/xylose mixtures. Enz Microb Technol 2009, 45:210-217.

8. Qian MY, Tian S, Li XF, Zhang J, Pan YP, Yang XS: Ethanol production from dilute-acid softwood hydrolysate by co-culture. Appl Biochem Biotechnol 2006, 134:273-283.

9. Mamma D, Koullas D, Fountoukidis G, Kekos D, Macris BJ, Koukios E: Bioethanol from sweet sorghum: Simultaneous saccharification and fermentation of carbohydrates by a mixed microbial culture. Process Biochem 1996, 31:377-381.

10. Collet C, Schwitzguebel JP, Peringer P: Improvement of acetate production from lactose by growing Clostridium thermolacticum in mixed batch culture. J Appl Microbiol 2003, 95:824-831.

11. Taniguchi M, Tokunaga T, Horiuchi K, Hoshino K, Sakai K, Tanaka T: Production of L-lactic acid from a mixture of xylose and glucose by cocultivation of lactic acid bacteria. Appl Microbiol Biotechnol 2004, 66:160-165.

12. Johnson MR, Conners SB, Montero Cl, Chou CJ, Shockley KR, Kelly RM: The Thermotoga maritima phenotype is impacted by syntrophic interaction with Methanococcus jannaschii in hyperthermophilic coculture. Appl Environ Microbiol 2006, 72:811-818.

13. Johnson MR, Montero Cl, Conners SB, Shockley KR, Bridger SL, Kelly RM: Population density-dependent regulation of exopolysaccharide formation in the hyperthermophilic bacterium Thermotoga maritima. Mol Microbiol 2005, 55:664-674.

14. Maligoy M, Mercade M, Cocaign-Bousquet M, Loubiere P: Transcriptome analysis of Lactococcus lactis in coculture with Saccharomyces cerevisiae. Appl Environ Microbiol 2008, 74:485-494.

15. Muddiman D, Andrews G, Lewis D, Notey J, Kelly R: Part II: defining and quantifying individual and co-cultured intracellular proteomes of two thermophilic microorganisms by GeLC-MS ${ }^{2}$ and spectral counting. Anal Bioanal Chem 2010, 398:391-404.

16. Stolyar S, Van Dien S, Hillesland KL, Pinel N, Lie TJ, Leigh JA, Stahl DA: Metabolic modeling of a mutualistic microbial community. Mol Syst Biol 2007, 3:92.

17. Kato S, Haruta S, Cui ZJ, Ishii M, Igarashi Y: Stable coexistence of five bacterial strains as a cellulose-degrading community. Appl Environ Microbiol 2005, 71:7099-7106.

18. Collet C, Gaudard O, Peringer P, Schwitzquebel JP: Acetate production from lactose by Clostridium thermolacticum and hydrogen-scavenging microorganisms in continuous culture - Effect of hydrogen partial pressure. J Biotechnol 2005, 118:328-338.

19. Drzyzga O, Gerritse J, Dijk JA, Elissen H, Gottschal JC: Coexistence of a sulphate-reducing Desulfovibrio species and the dehalorespiring Desulfitobacterium frappieri TCE1 in defined chemostat cultures grown 
with various combinations of sulphate and tetrachloroethene. Environ Microbiol 2001, 3:92-99.

20. Kato S, Haruta S, Cui ZJ, Ishii M, Igarashi Y: Network relationships of bacteria in a stable mixed culture. Microb Ecol 2008, 56:403-411.

21. Thomas S, Sarfaraz S, Mishra LC, lyengar L: Degradation of phenol and phenolic compounds by a defined denitrifying bacterial culture. World J Microbiol Biotechnol 2002, 18:57-63.

22. Hallenbeck PC, Ghosh D: Advances in fermentative biohydrogen production: the way forward? Trends Biotechnol 2009, 27:287-297.

23. Hawkes FR, Hussy I, Kyazze G, Dinsdale R, Hawkes DL: Continuous dark fermentative hydrogen production by mesophilic microflora: Principles and progress. Int J Hydrogen Energy 2007, 32:172-184.

24. $\mathrm{Li} \mathrm{CL}$, Fang HHP: Fermentative hydrogen production from wastewater and solid wastes by mixed cultures. Crit Rev Env Sci Tec 2007, 37:1-39.

25. Valdez-Vazquez I, Poggi-Varaldo HM: Hydrogen production by fermentative consortia. Ren Sust Energy Rev 2009, 13:1000-1013.

26. Hallenbeck PC: Fundamentals of the fermentative production of hydrogen. Water Sci Technol 2005, 52:21-29.

27. Thauer RK, Jungermann K, Decker K: Energy conservation in chemotropic anaerobic bacteria. Bacteriol Rev 1977, 41:100-180

28. Zeidan AA, van Niel EWJ: Developing a thermophilic hydrogen-producing co-culture for efficient utilization of mixed sugars. Int J Hydrogen Energy 2009, 34:4524-4528.

29. Liu Y, YU P, Song X, Qu YB: Hydrogen production from cellulose by coculture of Clostridium thermocellum JN4 and Thermoanaerobacterium thermosaccharolyticum GD17. Int J Hydrogen Energy 2008, 33:2927-2933.

30. Mori Y: Characterization of a symbiotic coculture of Clostridium thermohydrosulfuricum YM3 and Clostridium thermocellum YM4. Appl Environ Microbiol 1990, 56:37-42.

31. Rainey FA, Donnison AM, Janssen PH, Saul D, Rodrigo A, Bergquist PL, Daniel RM, Stackebrandt E, Morgan HW: Description of Caldicellulosiruptor saccharolyticus gen. nov., sp. nov.: An obligately anaerobic, extremely thermophilic, cellulolytic bacterium. FEMS Microbiol Lett 1994, 120:263-266.

32. Sissons $\mathrm{CH}$, Sharrock KR, Daniel RM, Morgan HW: Isolation of cellulolytic anaerobic extreme thermophiles from New Zealand thermal sites. Appl Environ Microbiol 1987, 53:832-838.

33. Bredholt S, Sonne-Hansen J, Nielsen P, Mathrani IM, Ahring BK: Caldicellulosiruptor kristjanssonii sp nov., a cellulolytic extremely thermophilic, anaerobic bacterium. Int J Syst Bacterio/ 1999, 49:991-996.

34. van de Werken $\mathrm{HJ}$, Verhaart MR, VanFossen AL, Willquist $\mathrm{K}$, Lewis DL, Nichols JD, Goorissen HP, Mongodin EF, Nelson KE, van Niel EWJ, Stams AJM, Ward DE, de Vos WM, van der Oost J, Kelly RM, Kengen SWM: Hydrogenomics of the extremely thermophilic bacterium Caldicellulosiruptor saccharolyticus. Appl Environ Microbiol 2008, 74:6720-6729.

35. Roels JA: Energetics and Kinetics in Biotechnology Amsterdam: Elsevier; 1983.

36. de Vrije T, Mars AE, Budde MAW, Lai MH, Dijkema C, de Waard P, Claassen PAM: Glycolytic pathway and hydrogen yield studies of the extreme thermophile Caldicellulosiruptor saccharolyticus. Appl Microbiol Biotechnol 2007, 74:1358-1367.

37. Hild HM, Stuckey DC, Leak DJ: Effect of nutrient limitation on product formation during continuous fermentation of xylose with Thermoanaerobacter ethanolicus JW200 Fe(7). Appl Microbiol Biotechnol 2003, 60:679-686.

38. Lu WY, Wen JP, Chen Y, Sun B, Jia XQ, Liu MH, Caiyin Q: Synergistic effect of Candida maltosa HY-35 and Enterobacter aerogenes W-23 on hydrogen production. Int J Hydrogen Energy 2007, 32:1059-1066.

39. Wang AJ, Ren NQ, Shi YG, Lee DJ: Bioaugmented hydrogen production from microcrystalline cellulose using co-culture - Clostridium acetobutylicum $\mathrm{X}_{9}$ and Ethanoigenens harbinense $\mathrm{B}_{49}$. Int I Hydrogen Energy 2008, 33:912-917.

40. Yokoi H, Tokushige T, Hirose J, Hayashi S, Takasaki Y: $\mathrm{H}_{2}$ production from starch by a mixed culture of Clostridium butyricum and Enterobacter aerogenes. Biotechnol Lett 1998, 20:143-147.

41. Kim SH, Han SK, Shin HS: Effect of substrate concentration on hydrogen production and 16S rDNA-based analysis of the microbial community in a continuous fermenter. Process Biochem 2006, 41:199-207.

42. Bisaillon A, Turcot J, Hallenbeck PC: The effect of nutrient limitation on hydrogen production by batch cultures of Escherichia coli. Int I Hydrogen Energy 2006, 31:1504-1508.
43. Turcot J, Bisaillon A, Hallenbeck PC: Hydrogen production by continuous cultures of Escherchia coli under different nutrient regimes. Int J Hydrogen Energy 2008, 33:1465-1470.

44. Gavala HN, Skiadas LV, Ahring BK: Biological hydrogen production in suspended and attached growth anaerobic reactor systems. Int $J$ Hydrogen Energy 2006, 31:1164-1175.

45. Kongjan P, Min B, Angelidaki I: Biohydrogen production from xylose at extreme thermophilic temperatures $\left(70^{\circ} \mathrm{C}\right)$ by mixed culture fermentation. Water Res 2009, 43:1414-1424.

46. Koskinen PEP, Lay CH, Puhakka JA, Lin PJ, Wu SY, Örlygsson J, Lin CY: Highefficiency hydrogen production by an anaerobic, thermophilic enrichment culture from an Icelandic hot spring. Biotechnol Bioeng 2008, 101:665-678.

47. Hardin G: The competitive exclusion principle. Science 1960 131:1292-1297.

48. van Niel EWJ, Claassen PAM, Stams AJM: Substrate and product inhibition of hydrogen production by the extreme thermophile, Caldicellulosiruptor saccharolyticus. Biotechnol Bioeng 2003, 81:255-262.

49. Willquist $K$, Claassen PAM, van Niel EWJ: Evaluation of the influence of $\mathrm{CO}_{2}$ on hydrogen production by Caldicellulosiruptor saccharolyticus. Int J Hydrogen Energy 2009, 34:4718-4726.

50. West SA, Griffin AS, Gardner A, Diggle SP: Social evolution theory for microorganisms. Nat Rev Microbiol 2006, 4:597-607.

51. Keller L, Surette MG: Communication in bacteria: an ecological and evolutionary perspective. Nat Rev Microbiol 2006, 4:249-258.

52. Shank EA, Kolter R: New developments in microbial interspecies signaling. Curr Opin Microbiol 2009, 12:205-214.

53. Miller MB, Bassler BL: Quorum sensing in bacteria. Annu Rev Microbiol 2001, 55:165-199.

54. Nichols D, Lewis K, Orjala J, Mo S, Ortenberg R, O'Connor P, Zhao C, Vouros P, Kaeberlein T, Epstein SS: Short peptide induces an "uncultivable" microorganism to grow in vitro. Appl Environ Microbiol 2008, 74:4889-4897.

55. Burmølle M, Webb JS, Rao D, Hansen LH, Sørensen SJ, Kjelleberg S: Enhanced biofilm formation and increased resistance to antimicrobial agents and bacterial invasion are caused by synergistic interactions in multispecies biofilms. Appl Environ Microbiol 2006, 72:3916-3923.

doi:10.1186/1475-2859-9-102

Cite this article as: Zeidan et al:: Stable coexistence of two Caldicellulosiruptor species in a de novo constructed hydrogenproducing co-culture. Microbial Cell Factories 2010 9:102.

\section{Submit your next manuscript to BioMed Central and take full advantage of:}

- Convenient online submission

- Thorough peer review

- No space constraints or color figure charges

- Immediate publication on acceptance

- Inclusion in PubMed, CAS, Scopus and Google Scholar

- Research which is freely available for redistribution

Submit your manuscript at www.biomedcentral.com/submit
C Biomed Central 